\title{
Pharmacotherapy in patients with chronic coronary syndromes over a 20-year period (1997-2017)
}

\author{
Piotr Jankowski', Paweł Kozieł', Piotr Bogacki², Piotr Gomuła ${ }^{3}$, Ewa Mirek-Bryniarska ${ }^{4}$, \\ Jadwiga Nessler ${ }^{5}$, Piotr Podolec ${ }^{6}$, Dirk De Bacquer', Guy De Backer7, Kornelia Kotseva ${ }^{8}$, \\ David Wood ${ }^{8}$, Danuta Czarnecka1', Kalina Kawecka-Jaszcz ${ }^{1}$, Andrzej Pająk ${ }^{9}$ \\ 1 1st Department of Cardiology, Interventional Electrocardiology and Hypertension, Institute of Cardiology, Jagiellonian University Medical College, Kraków, Poland \\ 2 Department of Cardiology, Ludwik Rydygier District Hospital, Kraków, Poland \\ 3 Department of Cardiology, Gabriel Narutowicz Memorial General Hospital, Kraków,Poland \\ 4 Department of Cardiology, Józef Dietl Hospital, Kraków, Poland \\ 5 Department of Coronary Heart Disease, Institute of Cardiology, Jagiellonian University Medical College, Kraków, Poland \\ 6 Department of Cardiac and Vascular Diseases, Institute of Cardiology, Jagiellonian University Medical College, Kraków, Poland \\ 7 Department of Public Health and Primary Care, Ghent University, Ghent, Belgium \\ 8 Imperial College Healthcare NHS Trust and National Institute of Preventive Cardiology, National University of Ireland-Galway, Galway, Ireland \\ 9 Department of Clinical Epidemiology and Population Studies, Institute of Public Health, Jagiellonian University Medical College, Kraków, Poland
}

Correspondence to: Prof. Piotr Jankowski, MD, $\mathrm{PhD}$, 1st Department of Cardiology, Interventional Electrocardiology and Hypertension, Institute of Cardiology, Jagiellonian University Medical College, ul. Jakubowskiego 2 30-688 Kraków, Poland, phone: +48124002150 email: piotrjankowski@interia.pl Received: July 8, 2020. Revision accepted: August 27, 2020. Published online: September 3,2020 Kardiol Pol. 2020; 78 (11): 1156-1158 doi:10.33963/KP.15591

Copyright by the Author(s), 2020
Introduction Cardiovascular disease is the leading cause of death in developed countries. ${ }^{1}$ Recent years have shown that mortality rates following myocardial infarction (MI) remain high-amounting to about $10 \%$ within a year after MI-despite the development of pharmacological and invasive methods of coronary artery disease (CAD) treatment. ${ }^{2}$ The main causes of high mortality following MI, among others, include unsatisfactory control of risk factors, insufficient lifestyle changes, and inadequate pharmacotherapy. ${ }^{3}$ Secondary prevention of cardiovascular events relies on lifestyle modification, risk factor control, and optimal pharmacotherapy. ${ }^{4-7}$ The aim of the present analysis was to assess trends regarding the use of the major drug classes in patients with chronic coronary syndromes within 2 decades.

Methods We analyzed the data of individuals who took part in 5 surveys assessing secondary prevention following hospitalization due to $\mathrm{CAD}$, carried out in the years 1997-1998, 1999-2000, 2006-2007, 2011-2013, and 2016-2017. ${ }^{8-12}$ The same 5 hospitals serving the city and surrounding districts participated in each survey. Methods used in surveys were published elsewhere and looked similar. ${ }^{8-13}$ Shortly, in each survey, the study sample consisted of consecutive patients hospitalized for coronary artery bypass grafting or percutaneous coronary intervention, or myocardial infarction, or unstable angina. As the age limit in the first (1997-1998) and the second (1999-2000) surveys was set below 71 years at the time of hospitalization, we excluded all older participants of the other 3 surveys from the present analysis.

The examination took part 6 to 18 months after the index hospitalization. Data on medications were obtained using a standard questionnaire and were based on the study patients' declarations. Survey protocols were approved by the institutional bioethics committee. All patients signed an informed consent form.

Statistical analysis Categorical variables were expressed as percentages, and continuous variables, as mean (SD). The Pearson $\mathrm{X}^{2}$ test was applied to all categorical variables. Normally distributed continuous variables were compared using the analysis of variance. Variables with non-normal distribution were evaluated using the Kruskal-Wallis analysis of variance. A generalized linear model (logit model), as implemented in the Statistica 13 software (TIBCO Software, Palo Alto, California, United States), 
TABLE 1 Prescription rates of drug classes at 6 to 18 months after hospitalization due to the index event

\begin{tabular}{|c|c|c|c|c|c|c|c|}
\hline \multicolumn{2}{|l|}{ Drug class } & $\begin{array}{l}1997-1998 \\
(n=418)\end{array}$ & $\begin{array}{l}1999-2000 \\
(n=427)\end{array}$ & $\begin{array}{l}2006-2007 \\
(n=425)\end{array}$ & $\begin{array}{l}2011-2013 \\
(n=469)\end{array}$ & $\begin{array}{l}2016-2017 \\
(n=274)\end{array}$ & $P$ value \\
\hline \multicolumn{2}{|c|}{ Antiplatelets (at least 1 agent) } & 76.1 & 86.9 & 90.1 & 90 & 96.7 & $<0.001$ \\
\hline \multicolumn{2}{|l|}{$\beta$-Blockers } & 59.1 & 63.9 & 87.5 & 80.8 & 92.7 & $<0.001$ \\
\hline \multirow[t]{3}{*}{ ACEIs/sartans } & Any & 45.9 & 47.5 & 79 & 76.8 & 89.1 & $<0.001$ \\
\hline & ACEIs & 45.9 & 47.5 & 74.6 & 66.1 & 74.8 & $<0.001$ \\
\hline & Sartans & 0 & 0 & 5.4 & 12.6 & 14.2 & $<0.001$ \\
\hline \multicolumn{2}{|l|}{ Calcium antagonists } & 28.7 & 33.3 & 20.9 & 21.1 & 27.7 & $<0.001$ \\
\hline \multicolumn{2}{|l|}{ Diuretics } & 17 & 21 & 31.8 & 36.3 & 41.2 & $<0.001$ \\
\hline \multirow[t]{4}{*}{ Lipid-lowering drugs } & Any & 33.7 & 41.9 & 86.8 & 83.4 & 90.8 & $<0.001$ \\
\hline & Statins & 19.4 & 34.2 & 85.4 & 83.2 & 90.5 & $<0.001$ \\
\hline & Fibrates & 14.1 & 7.7 & 3.5 & 2.6 & 1.1 & $<0.001$ \\
\hline & Ezetimibe & 0 & 0 & 0.2 & 0.6 & 3.3 & $<0.001$ \\
\hline \multicolumn{2}{|l|}{ Antidiabetic agents } & 10.3 & 13.4 & 19.6 & 25.6 & 34.3 & $<0.001$ \\
\hline \multicolumn{2}{|l|}{ Anticoagulants } & 12.4 & 5.6 & 6.4 & 5.4 & 13.1 & $<0.001$ \\
\hline
\end{tabular}

Data are presented as percentage.

a Adjusted for sex, age, education, and index event

Abbreviations: ACEIs, angiotensin-converting enzyme inhibitors

was used to compare proportions of patients using drugs from particular classes, and the model was adjusted for sex, age, education, and index event. A 2-tailed $P$ value less than 0.05 was considered significant.

Results and discussion The number of survey participants was as follows: 418 in 1997-1998, 427 in 1999-2000, 425 in 2006-2007, 469 in 2011-2013, and 274 in 2016-2017. The mean (SD) age of the study participants was 57.8 (8.3) years in 1997-1998, 58.6 (8.1) years in 1999-2000, 59.9 (7.6) years in 2006-2007, 61.1 (6.9) years in 2011-2013, and 62.6 (6.9) years in 2016-2017 $(P<0.001)$. There was no significant difference in sex distribution between surveys (in total, $70.9 \%$ of men and $29.1 \%$ of women), whereas the mean (SD) duration of education gradually increased: 11.4 (3.6) years in 1997-1998, 11.6 (3.5) years in 1999-2000, 11.9 (3.4) years in 2006-2007, 12.1 (3.1) years in 2011-2013, and 13 (3.1) years in 2016-2017 ( $P<0.001)$.

Crude proportions of patients taking antiplatelet agents, $\beta$-blockers, angiotensin-converting enzyme inhibitors / sartans, calcium antagonists, diuretics, anticoagulants, lipid-lowering drugs, and antidiabetic agents are presented in TABLE 1. In univariate analysis, we observed significant differences in the use of all analyzed drug classes. Multivariate adjustments did not influence the results significantly (TABLE1).

Evidence suggests that survival in patients with CAD may be improved through providing optimal secondary prevention, which includes the control of main risk factors and optimal pharmacotherapy. ${ }^{4,6,7}$ Our analysis provided evidence for a substantial improvement with respect to all drug classes, which improves prognosis in patients with CAD, including postinfarction patients and those with heart failure. The differences found in drug use could not be explained by differences in the mean age and education only. It seems that the increasing drug uptake reflects both the increasing prevalence of hypertension, heart failure, diabetes, and other diseases as well as improvement in the quality of treatment of these conditions. Interestingly, larger differences could be seen in the decade 1997/1998-2006 / 2007 than in the years 2006/2007-2016/2017. This could be related to the rising awareness regarding the significance of guideline implementation at the beginning of the current century. It should be, however, emphasized that despite a considerable increase in cardiovascular drug use over the 20-year period, the wider use of "newly" developed drugs, including protein convertase subtilisin/kexin type 9 inhibitors, type 2 renal sodium-glucose cotransporter inhibitors, ticagrelor, new antithrombotic agents, and angiotensin receptorneprilysin inhibitor, could further decrease cardiovascular risk. In addition, our findings should be interpreted in the light of studies that show high rates of CAD patients with uncontrolled risk factors. ${ }^{13-15}$

Numerous studies assessing the quality of medical care in the field of secondary prevention of $C A D$, including the prescription rates 
of cardiovascular drugs, have been published so far. ${ }^{13,14}$ To our best knowledge, the present study analyzed the only available data that allow one to estimate the operational efficiency of the same hospitals in the secondary prevention of CAD over 20 years. This provides a unique opportunity to track long-term changes in prescription rates in patients with CAD who lived in a defined area and were hospitalized in the same hospitals.

Admittedly, our analysis had several limitations. Although our results were obtained from consecutive surveys conducted in patients with established CAD who were inhabitants of the same area, the observation was restricted to those who experienced an acute CAD event or underwent a revascularization procedure. Therefore, the study participants were not representative of all patients with CAD and the applicability of the results to other regions remains uncertain. On the other hand, the demonstrated trends correspond with short-term changes observed in patients with CAD in other European countries. ${ }^{15}$ Study groups could differ with respect to the number of unidentified factors, which could explain the discrepancies. It also needs to be noted that most of the analyzed drug classes should be prescribed in particular conditions depending on left ventricular function, blood pressure, glucose metabolism, heart rate, presence of angina or arrhythmia, etc. Therefore, one should not expect that agents from a particular drug class were prescribed in $100 \%$ of the analyzed patients.

In conclusion, the analysis of 5 multicenter surveys provided evidence for a gradual increase in the uptake of the major groups of cardiovascular drugs in patients with chronic coronary syndromes over a 20-year period.

\section{ARTICLE INFORMATION}

\section{CONFLICT OF INTEREST None declared.}

OPEN ACCESS This is an Open Access article distributed under the terms of the Creative Commons Attribution-NonCommercial-NoDerivatives $4.0 \mathrm{In}$ ternational License (CC BY-NC-ND 4.0), allowing third parties to download articles and share them with others, provided the original work is properly cited, not changed in any way, distributed under the same license, and used for noncommercial purposes only. For commercial use, please contact the journal office at kardiologiapolska@ptkardio.pl.

HOW TO CITE Jankowski P, Kozieł P, Bogacki P, et al. Pharmacotherapy in patients with chronic coronary syndromes over a 20-year period (1997-2017). Kardiol Pol. 2020; 78: 1156-1158. doi:10.33963/KP.15591

\section{REFERENCES}

1 Wilkins E, Wilson L, Wickramasinghe K, et al. European Cardiovascular Disease Statistics 2017. Brussels: European Heart Network; 2017.

2 Gierlotka M, Zdrojewski T, Wojtyniak B, et al. Incidence, treatment, in-hospital mortality and one-year outcomes of acute myocardial infarction in Poland in 2009-2012 - nationwide AMI-PL database. Kardiol Pol. 2015; 73: 142-158.

3 Jankowski P, Gassior M, Gierlotka M, et al. Coordinated care after myocardial infarction. The statement of the Polish Cardiac Society and the Agency for Health Technology Assessment and Tariff System. Kardiol Pol. 2016; 74: 800-811.

4 Piepoli MF, Hoes AW, Agewall S, et al. 2016 European Guidelines on cardiovascular disease prevention in clinical practice. The Sixth Joint Task Force of the European Society of Cardiology and Other Societies on Cardiovascular Disease Prevention in Clinical Practice. Eur Heart J. 2016; 37: 2315-2381.
5 Knuuti J, Wijns W, Saraste A, et al. 2019 ESC Guidelines for the diagnosis and management of chronic coronary syndromes: the Task Force for the Diagnosis and Management of Chronic Coronary Syndromes of the European Society of Cardiology. Eur Heart J. 2019; 41: 407-477.

6 Maron DJ, Hochman JS, Reynolds HR, et al. Initial invasive or conservative strategy for stable coronary disease. N Engl J Med. 2020; 382: 1395-1407.

7 Hasenfuß G. Secondary prevention of cardiovascular diseases: current state of the art. Kardiol Pol. 2018; 76: 1671-1679.

8 Kawecka-Jaszcz K, Pająk A, Jankowski P, et al. Krakow Program for secondary prevention of ischaemic heart disease. Part III. Secondary prevention of ischaemic heart disease after discharge. Przegl Lek. 2001; 58: 964-968.

9 Jankowski P, Kawecka-Jaszcz K, Pajak A, et al. Cracovian program for secondary prevention of ischemic heart disease. Secondary prevention of ischemic heart disease after discharge in 1997-98 and 1999-2000. Przegl Lek. 2003; 60: 142-146.

10 Pajak A, Jankowski P, Kawecka-Jaszcz K, et al. Changes in secondary prevention of coronary artery disease in the post-discharge period over the decade 1997-2007. Comparison of Cracovian Program for Secondary Prevention of Ischaemic Heart Disease and Polish parts of EUROASPIRE II and EUROASPIRE III surveys. Kardiol Pol. 2009; 67: 1353-1359.

11 Jankowski P, Czarnecka D, tysek R, et al. Secondary prevention in patients after hospitalization due to coronary artery disease: what has changed since 2006? Kardiol Pol. 2014; 72: 355-362.

12 Jankowski P, Kosior DA, Sowa P, et al. Secondary prevention of coronary artery disease in Poland. Results from the POLASPIRE survey. Cardiol J. 2020 May 21. [Epub ahead of print].

13 Kotseva K, De Backer G, De Bacquer D, et al. Lifestyle and impact on cardiovascular risk factor control in coronary patients across 27 countries: results from the European Society of Cardiology ESC-EORP EUROASPIRE V registry. Eur J Prev Cardiol. 2019; 26: 824-835.

14 Komajda $M$, Cosentino F, Ferrari $R$, et al. Profile and treatment of chronic coronary syndromes in European Society of Cardiology member countries: the ESC EORP CICD-LT registry. Eur J Prev Cardiol. 2020 Mar 31. [Epub ahead of print].

15 Kotseva K, De Bacquer D, Jennings C, et al. Time trends in lifestyle, risk factor control, and use of evidence-based medications in patients with coronary heart disease in Europe: results from 3 EUROASPIRE surveys, 1999-2013. Glob Heart. 2017; 12: 315-322. 